\title{
Root-shoot interactions and plant life forms
}

\author{
E.-D. Schulze \\ Lehrstuhl Pflanzenökologie der Universität Bayreuth, Universitätsstrasse 30 , \\ D-8580 Bayreuth, West Germany
}

Key-words: root/shoot ratios, carbon partitioning, water relations, plant life forms

\section{Summary}

A great variety of plant life forms exists in natural vegetations which show different possible solutions to the same problem of carbon-partitioning, namely maintenance of carbon flows under limited access of water and nutrients. The interactions of water and nutrient flows on carbon relations are explained and typical features of root/shoot ratios in perennial plants and woody species are discussed. For a hydrostable annual crop plant it is shown that partitioning is controlled by transpiration rate per leaf area and by the capacity of the root for water uptake. For perennial woody species the significance of plant architecture and morphology is demonstrated for a situation of competitive growth. The occurrence of evergreen and deciduous foliage of woody species is explained with respect to habitat preference and plant geography.

\section{Introduction}

The life of higher plants depends on the maintenance of a positive carbon balance in a situation of permanent nutrient and water demand. Therefore, plant production can only be understood on a functional basis with insight into whole plant carbon, water and nutrient relations. In natural vegetation, plant production serves primarily the survival and the long-term persistence of the individual plant under competition by neighbouring plants. In many cases the persistence over very long time spans is critical, as for instance in forest trees which become fertile only after several decades.

During evolution plants have responded to the climatic and edaphic conditions of habitats by developing a great variety of plant life forms, which have characteristic features of carbon turnover and distribution, and corresponding differences in nutrient and water use. Specific plant life forms appear to be successful under certain habitat conditions. In fact, different life forms have invaded all habitats of this earth, from cold alpine or arctic climates to extreme desert heat and drought, and from saline sea shores to the most extreme conditions of nutrient deficiencies. The vegetation of the earth is characterized by distinct zones, which have a rather uniform physiognomical appearance or structure even though they may be composed of many different taxa. The convergence of morphological structures in plant com- 
munities is the result of habitat specific demands on the functional equilibrium of root/shoot interactions and carbon, water and nutrient turn-over, which result in differences of plant life forms (review Schulze, 1982).

It is the aim of the present paper to describe and to explain the specific root/shoot interactions of various plant life forms. Although an enormous amount of work has been carried out with agricultural plants, such work is mainly concerned with annual crop species, and harvests were generally of the above-ground parts only. One impact of the International Biological Program was that complete biomass data were assembled for all major vegetation zones. But this knowledge does not allow sufficient insight into the interactions of the carbon, water and nutrient flows which determine the functional equilibrium of root and shoot in different plant life forms with respect to habitat conditions. In fact, our knowledge of carbon, water and nutrient relations of the natural-vegetation species is very limited, and therefore, the following discussion can only be based on a few examples, which certainly do not cover the full range of possible response types.

\section{Dry-matter production as related to water and nutrient flows}

Various plant formations show a distinct and characteristic partitioning of biomass into organs, namely leaves, stems and roots (Table 1). Large differences exist between vegetation zones with respect to total biomass, ranging from about $90 \mathrm{~kg} \mathrm{~m}^{-2}$ in rain forests and boreal forests to $0.1 \mathrm{~kg} \mathrm{~m}^{-2}$ in deserts and tundras. The investment of carbohydrates in the leaves shows an inversed pattern. In most forest ecosystems the plant is sustained by a minute proportion of green foliage, whereas the corresponding proportion is considerably larger for herbaceous plant formations. The root/shoot ratio changes from about 1 in meadow species to 0.1 in woody species.

The biomass data of Table 1 show distinct habitat-related differences, but they

Table 1. Biomass, net primary production, and $\mathrm{CO}_{2}$-assimilating organs, stems and roots (as a percentage of total biomass) in various plant formations. (After Larcher, 1980 and Schulze, 1982.)

\begin{tabular}{lccccc}
\hline Plant & $\begin{array}{l}\text { Biomass } \\
\left(\mathrm{kg} \mathrm{m}^{-2}\right)\end{array}$ & $\begin{array}{l}\text { Net primary } \\
\text { production } \\
\left(\mathrm{kg} \mathrm{m}^{-2}\right)\end{array}$ & $\begin{array}{l}\mathrm{CO}_{2} \text {-assimi- } \\
\text { lating organs } \\
(\%)\end{array}$ & $\begin{array}{l}\text { Above- } \\
\text { ground } \\
\text { stems }(\%)\end{array}$ & $\begin{array}{l}\text { Below-ground } \\
\text { stems and } \\
\text { roots }(\%)\end{array}$ \\
$\begin{array}{l}\text { Evergreen trees of tropical and } \\
\text { subtropical forests }\end{array}$ & $41-65$ & $6-17$ & $1-2$ & $80-90^{*}$ & $10-20^{*}$ \\
$\begin{array}{l}\text { Deciduous trees of temperate } \\
\text { forests }\end{array}$ & $18-60$ & $0.4-2.5$ & $1-2$ & $80^{*}$ & $20^{*}$ \\
$\begin{array}{l}\text { Evergreen trees of boreal forests } \\
\text { Alpine 'Krumholz' species }\end{array}$ & $20-90$ & $0.2-1.5$ & $4-5$ & $75^{*}$ & $20^{*}$ \\
Ericaceae heath species & $5-10$ & $0.1-0.5$ & 25 & $30^{*}$ & $45^{*}$ \\
Gramineae species & $1-6$ & $0.1-0.5$ & $10-20$ & $20^{*}$ & $60-70^{*}$ \\
$\begin{array}{l}\text { Desert plants } \\
\text { Alpine plants }\end{array}$ & $2-3$ & $0.1-1.3$ & $30-50$ & & $50-70$ \\
\hline
\end{tabular}

* A large proportion of biomass is dead wood. 
are difficult to interpret, since they describe the plant stand like a photograph would describe a process in motion. Generally these data do not allow an estimate of how net primary production would change if one or the other factor would vary. Therefore, the degree of 'adaptation' is not obvious, since it is not clear what effect a change in partitioning and in root/shoot ratio would have on the total production process. There is no 'standard' with which to compare the existing pattern of carbon-partitioning. It is quite obvious that the light climate, the water and the nutrient conditions regulate this process, but for plants of natural vegetation, in general, it has not been possible thus far to describe these interactions of factors on a functional basis in such a way that ecological conclusions could be derived.

The photosynthetic carbon gain of a plant is a function of the rate of $\mathrm{CO}_{2}$ assimilation and the amount of leaf tissue. At the level of photosynthesis, plants have one important mechanism for regulating both $\mathrm{CO}_{2}$ and $\mathrm{H}_{2} \mathrm{O}$ fluxes, i.e. the stomata. To describe plant growth, it is convenient to distinguish between growth of green photosynthesizing biomass and of non-green supporting biomass. The regulation of the partitioning of photosynthate between green and non-green tissue has special significance for the growth and success of plant life forms under particular ecological conditions. In nature, an extremely broad spectrum of carbon partitioning occurs. Autotrophic parasites, as for instance mistletoes, maximize leaf production, but they need trees as supporting structures for water and nutrient supply. Heterotrophic parasites maximize production of non-green tissue, but they need carbohydrate supply from their hosts.

Net primary production equals the increment of both green and non-green biomass, but the living biomass may be quite different from the simple additive effects of growth rate and initial biomass, since continuously senescence, death and abscission of living tissue occur at the same time. The turnover rate may also be quite different in roots and in leaves. Very different types of transfer from living to dead tissue occur in different plant life forms. The dying tissue may have completed its function and may be shed, e.g. leaves. But dying tissue may also remain an essential and functional part of the individual, e.g. wood. In this case a functional part of the plant does not require maintenance respiration, which is an energetic advantage.

It is quite clear that production of new foliage has a positive feedback upon the total production process. But this is not without limitations, since the plant will now need additional water and nutrients. After a certain leaf area index has been reached, self-shading will also reduce production, depending on leaf shape and angle. In many habitats the availability of light, affected by for instance self-shading, is a primary factor controlling production. Since this interaction is well understood (de Wit, 1968), the following analysis will concentrate on the interactions of plant water and nutrient relations.

Plant water relations are determined by the balance of uptake through the roots and water loss from the leaves, in a situation where the flow of water through the plant is orders of magnitude larger than growth requires. Neglecting soil and atmospheric conditions, water uptake is dependent on the water uptake rate per unit mass of the root and on the total root mass, which includes both the absorbing fine roots and the necessary supporting and conducting root structures. Plant water loss 

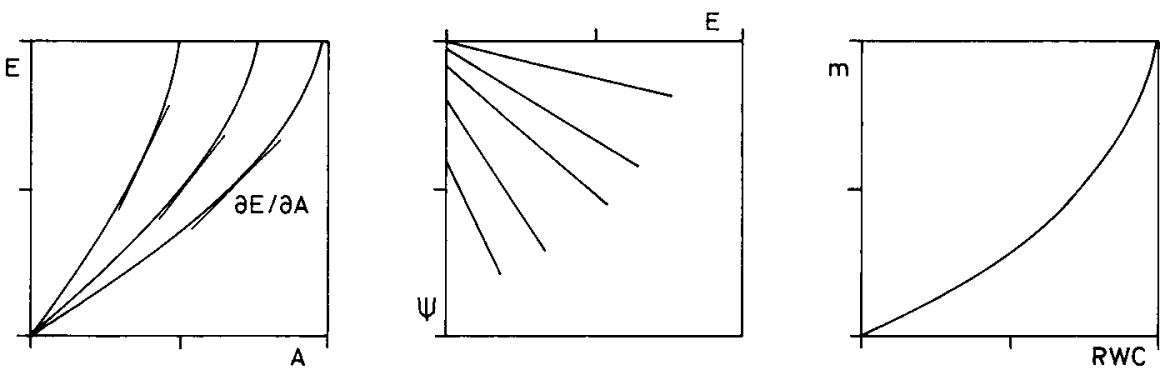

Fig. 1a (left). Relations between transpiration, $E$, and $\mathrm{CO}_{2}$ uptake, $A$, during various conditions of photosynthesis, e.g. variable light. The slope of the lines represents the marginal gain of photosynthesis during water loss. Fig. $1 \mathrm{~b}$ (middle). Relation between transpiration, $E$, and plant water potential, $\Psi$, at increasing soil drought. The slope of the lines represents the conductance within the soil/plant system. With increasing drought the water potential at zero transpiration decreases (intercept of y-axis). At the same time also the resistance of the water flow through the plant increases (increasing slope of the lines). Fig. 1c (right). The relation between partitioning of carbohydrates into leaves, $m$, and relative water content, RWC (after de Wit, 1968).

on the other hand, is related to transpiration per leaf area and total leaf area. Plant water relations and the $\mathrm{CO}_{2}$ assimilation process are closely coupled, as both the $\mathrm{CO}_{2}$ uptake and the water loss through transpiration follow the same diffusion pathway, i.e. the stomata.

The relation between $\mathrm{CO}_{2}$ uptake $(A)$ and transpiration $(E)$ is described by an exponentially increasing curve (Fig. $1 \mathrm{~A}$ ). $\mathrm{CO}_{2}$ uptake is limited by biochemical processes in the mesophyll, whereas transpiration is only dependent on the evaporative conditions of the atmosphere. The slope of the $E / A$ curves is defined as the marginal gain for $A$ with an increase in water use, $\delta E / \delta A$. It was proposed by Cowan and Farquhar (1977) that a plant is most efficient in its water use under various environmental conditions and stomatal responses when the marginal gain remains constant. Hall and Schulze (1980) found that this may in fact be observed under conditions of variable humidity and temperature, as long as there is an adequate water supply. The interactions between plant water status and stomatal function are difficult to analyze, since $\Psi$ is dependent upon $E$ (Fig. 1B). Moreover the slope of the $\Psi / E$ relationship is dependent on the flow resistance within the soil-root-leaf pathway. Schulze et al. (1983b) found that the water potential in the leaf has in fact little influence on stomatal opening, but that the water status in the root regulates the opening of the stomata. Water relations also affect carbon-partitioning. The crop growth model of de Wit (1968) assumes a decrease of the proportion of carbohydrates for growth of leaves, $m$, whenever the relative leaf water content, RWC, decreases (Fig. 1C).

Similar to water relations, plant nutrient relations determine in many ways the primary production and carbon-partitioning processes. But, there is a significant difference between water related and nutrient related processes. Storage and incorporation of water in growth processes is quantitatively insignificant, except in some specialized cases such as succulents, whereas in the case of nutrients considerable 
storage occurs. Moreover, the uptake of nutrients may be at a different time than their use, or the uptake is directly used for growth. Additionally, stored nutrients may or may not be accessible. The nutrient relations control photosynthesis via protein synthesis. In most species the capacity for fixing $\mathrm{CO}_{2}$ is related to the nitrogen content of the leaf. Nutrient relations also influence partitioning, if nutrient supply is limited, carbohydrate-partitioning favours root growth.

\section{Carbon partitioning in plant life forms}

The carbon partitioning into plant organs and the longevity of the plant individual and its organs are major characteristics, which determine the functional equilibrium between root and shoot, which in its turn determines life forms. The control of carbon partitioning by the plant water and nutrient relations determines the success of specific plant life forms under different environmental conditions.

Many attempts have been made to describe the physiognomic aspects of the earth's vegetation. Two different approaches have emerged: the first one was inductive and descriptive, the second one deductive. An attempt was made to explain morphological and structural features of plants and their pattern of occurrence under specific habitat conditions on a functional basis. The difficulty with this approach was that very often the expected result of the analysis was used as input in order to formally express 'strategies' and 'adaptations'. Monsi (1960) classified plant forms into annuals and perennials on the basis of carbon partitioning; the perennials were further divided into being either herbaceous or woody and the woody plants were classified into deciduous and evergreen forms. This classification will be used in the following brief description of carbon partitioning in different plant life forms (for further details see Schulze, 1982).

\section{Annuals}

Annuals have a short life cycle. Their non-photosynthetic organs are generally herbaceous and respiring. Their main feature is the completion of the whole life cycle in a very short time span with a large seed production, this being one reason for their success as crop plants. In order to accomplish rapid growth, carbohydrates of annuals are mainly channelled into the formation of new leaves, which promotes rapid development. Root growth is small and follows leaf expansion (Fig. 2). Only later in the life cycle carbohydrates are used for culm and seed formation. The success of annuals in natural vegetation depends strongly on seed formation. Therefore, the harvest index is higher than in any other plant form.

Since the large number of seeds determines the number of descendants, annuals are most successful in colonizing bare land. But this same feature may cause strong intraspecific competition after a few generations. The rapid growth and use of all available nutrient and water resources make annuals a predominant part of the vegetation in arid regions after periods of rainfall. However, since the life cycle must be completed within the same growing period, annuals are not very successful in the arctic-alpine vegetation where they contribute less than $1 \%$ to the flora.

The amount of carbohydrates which can be accumulated by annuals is deter- 

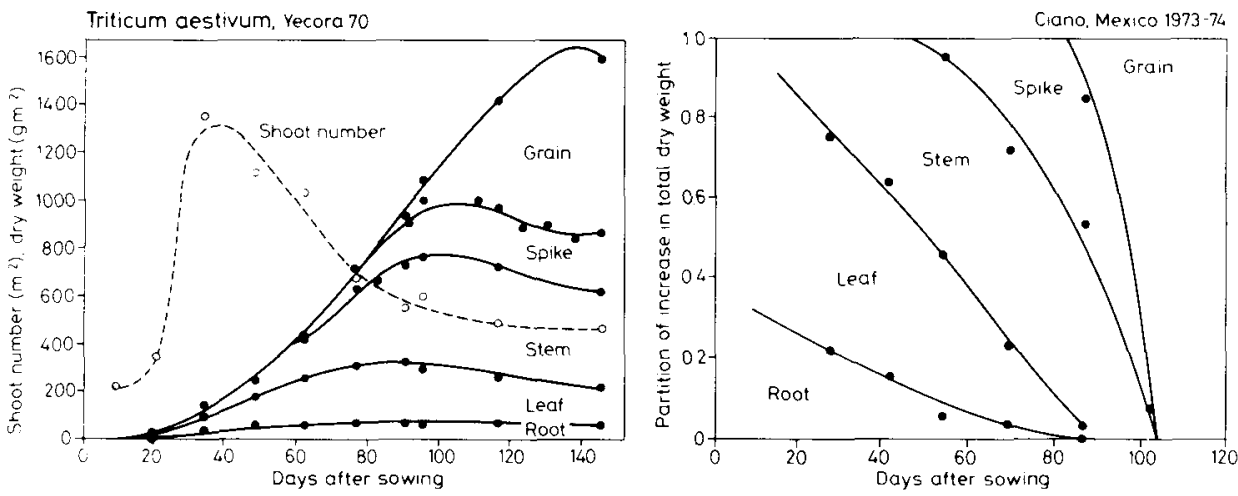

Fig. 2a (left). Distribution of total dry weight (including roots) and shoot number during development in a crop of the dwarf spring wheat cultivar Yecora 70 , grown under optimal agricultural conditions (after Fischer, 1975). Fig. 2b (right). Approximate dry-weight distribution in various organs of a wheat plant during increase in total dry weight at different times in the life of the canopy shown in Fig. 2a. The figures do not show transfer of dry matter from one organ to another after temporary storage in the former. Transfer from the stem, which decreases in dry weight, to grain, thereby augmenting its increase in dry weight, is quite important from day 110 onwards (after Fischer, 1975).

mined by the length of the growing season. In order to overcome this limitation, numerous transitions towards a perennial habit occur in temperate climates, for example winter annuals, e.g. winter wheat, and biennial plants, which grow vegetatively for one year and form seeds in the following year.

\section{Perennial herbaceous plants}

The main feature of perennial plants is the capacity of storage in order to ensure survival through the next season. Stored lipids and carbohydrates also allow a rapid start of growth early in the season. Perennials ensure the survival of the individual, therefore flowering and seed formation may or may not occur in a particular season. In a succession perennials are slower to start, because only a small portion of carbohydrates is partitioned into formation of new leaves. With the development of a larger root system and with a rapid start and prolonged growth in the early and late season, however, perennials will 'outcompete' an annual-plant population.

It is very difficult to describe a functional root/shoot equilibrium in perennial herbaceous plants, because the belowground part serves not only for water and nutrient uptake but also as storage. The size of the store may undergo significant seasonal changes and only a small proportion may serve for plant enlargement (Fig. 3). In Dupontia fisheri only $13 \%$ of the carbon gain of a young tiller is partitioned into rhizomes. Most of these carbohydrates are received in the tips and used for rhizome enlargement with only a small part of the carbohydrates being partitioned to older rhizome parts. Tillers of the older rhizome parts store carbohydrates within their tiller or in their rhizome segment until it is sufficient for flowering. Similar results were observed with another graminoid (Tietema, 1981).

Perennial herbaceous plants are most successful in environments where cold 
ROOT-SHOOT INTERACTIONS AND PLANT LIFE FORMS

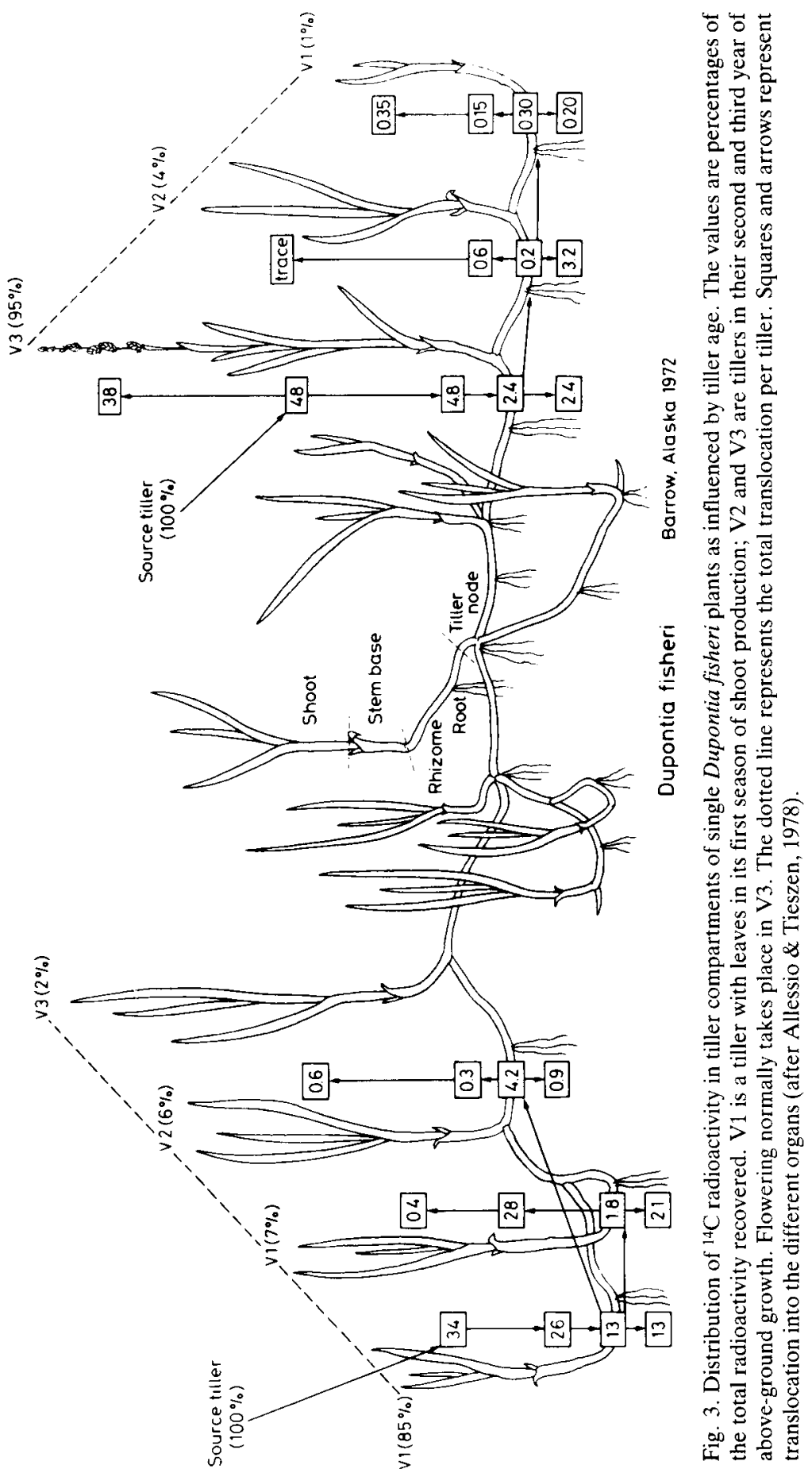

Neth. J. agric. Sci. 31 (1983) 
temperatures, shade, seasonal drought, wetness or mechanical disturbance create extreme but stable conditions such as in tropical grasslands, alpine meadows or forest floor vegetation. They lose efficiency when the probability of rainfall is low or the rainy season is of short duration, in which case annuals are more successful.

There is an upper limit to which perennial herbaceous species can grow, due to the increasing respiratory load of the non-photosynthesizing parts. At constant leaf area index net primary production becomes zero. This limitation of the herbaceous structure with respect to respiration and carbon balance is overcome by woody species.

\section{Woody plants}

Woody plants are characterized by secondary growth and by the continuous conversion of structural tissue into non-living, and therefore non-respiring biomass, which, however, remains an integral part of the individual, essential to its functioning. In woody plants the biomass of stems and roots therefore increases continually over time. The secondary growth of wood is the major distinction between herbaceous and woody plant life forms. However, because of the competitive importance of the growth in height it appears justified to distinguish between shrubs and trees, based on the degree of apical dominance.

Carbon partitioning and existing long-lived biomass leads to a situation where the relative proportion of leaves decreases continually (Fig. 4). Carbon partitioning into leaves does not change significantly beyond the age of 30 in Larrea tridenta$\mathrm{ta}$, although total biomass still increases.
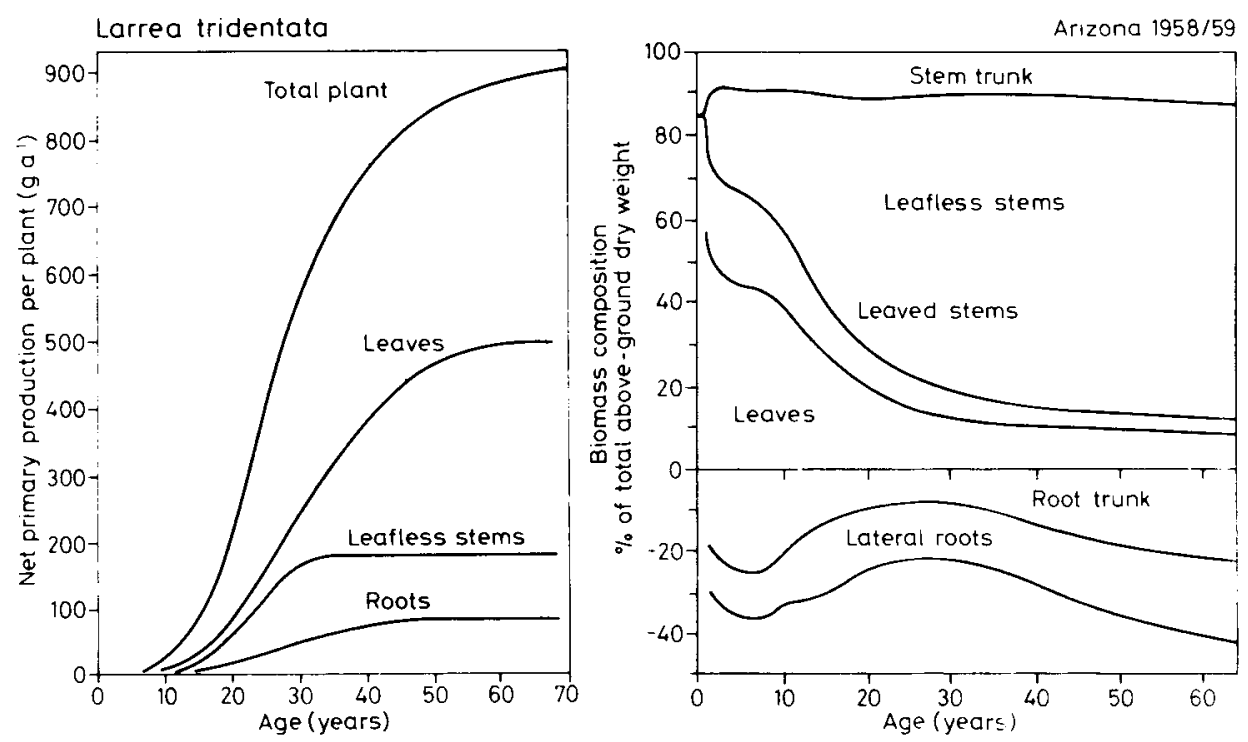

Fig. 4. Distribution of annual primary production in different organs and estimated relative composition of the shoot and root of Larrea tridentata of different ages (after Chew \& Chew, 1965). 


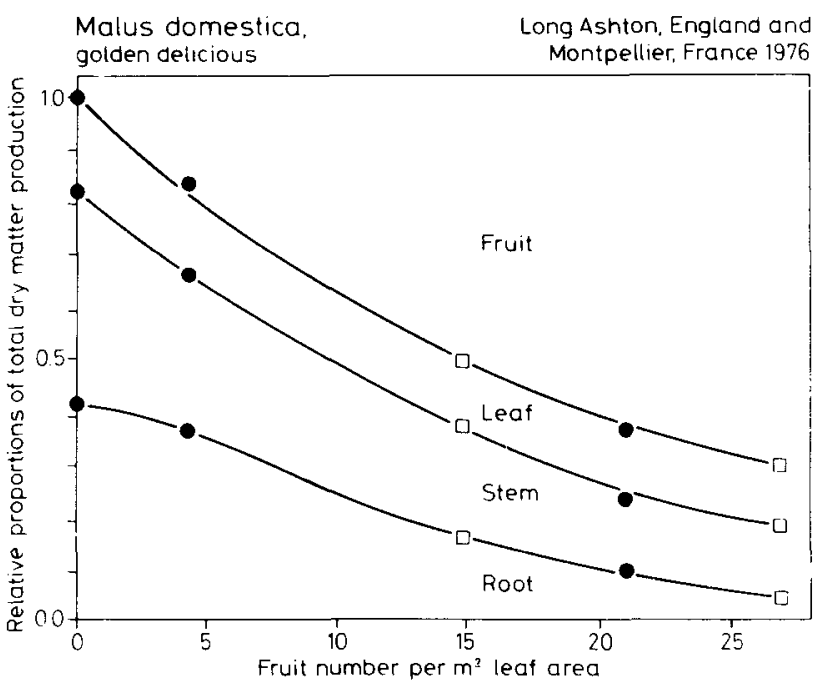

Fig. 5. Relative proportions of total dry-matter production as related to fruit number per leaf area in Malus domestica (after Heim et al., 1979).

In woody species there appears to be a competitive relationship for carbon part1tioning between wood and fruit formation (Fig. 5). In apple, the leaf production is constant during years of high and low fruit set, but wood production is inversely related to fruit biomass.

Carbon relations may reach another level of complication in woody species, since a large variation in leaf longevity has direct effects on the root/shoot equilibrium. Mesophytic leaves appear to be of advantage with respect to production. They reach a high carbon gain with little carbon investment. Therefore, we find this type of leaf in many herbaceous and woody species. But, all factors which reduce photosynthesis, i.e. low light and low temperatures, reduce carbon gain from photosynthesis. If the plant is to continue growth of non-photosynthetic organs at the same rate as under favourable conditions, the proportion of carbon partioned into leaves must be reduced. In order to maintain a constant leaf area index, it is necessary that the longevity of foliage increases. This requires greater carbon investments for production in adverse climates, which again promotes a shift in carbon relations towards one that favours perennial leaves. The change from deciduous to evergreen habits can be observed when comparing temperate deciduous and boreal evergreen forests.

Nutrient deficiency has similar effects. It reduces the carbon input by lowering the rate of photosynthesis per leaf area. Moreover, more carbohydrates are necessary for nutrient uptake, which in a feedback leads to perennial foliage as described above. This situation can be observed in tropical wet forests and in sclerophyllous shrublands as in Australia. 
Water stress would tend to operate in the same direction. But, there is an important distinction between plant water relations and nutrient relations, namely that there is very little water storage, with the exception of bottle trees and succulents. Therefore, the length of the drought period determines the functional equilibrium and the leaf form. Shallow rooted species are generally deciduous, whereas deeper rooted desert shrubs remain evergreen during drought.

\section{Carbon partitioning as a control process}

It is not possible so far to explain fully the root/shoot interactions of different plant life forms on a functional basis. An attempt is made to give insight into the control process by two examples, namely the growth of an annual under constraints of water use and the growth of woody species with respect to plant architecture.

Control of root/shoot growth under constraints of water use may be described in such a way that new leaves result in a positive feedback upon the production process, and new roots have positive feedback upon improving plant water status. It is suggested that annuals will maximize total biomass over a given time span as long as water loss does not reduce plant water content below a certain level. If for a given time span net primary production should reach a certain rate, regulation of root/shoot growth would be considered optimal if the balance between potential uptake and actual loss of water remains constant. In a hydrostable annual the regulation of the carbohydrate partitioning is controlled in such a way that the relative water content of the leaves only decreases below $90 \%$ under the most extreme conditions of drought (Nagarajah \& Schulze, 1983).

If Vigna unguiculata, a hydrostable plant, is grown well watered but under two different humidity regimes, one observes distinct differences in total biomass. Transpiration and growth per leaf area is distinctly smaller in dry than in humid air, without changes in plant water status. Carbon partitioning can be calculated using Equations 1 and 2 (Schulze et al., 1983):

$$
m(t)=1 /(1+c)
$$

when the root is sufficiently large to meet the water demand of the newly grown leaves, and

$$
m(t)=f^{\prime}\{R(t)\} /\left[k E+(1+c) f^{\prime}\{R(t)\}\right]
$$

when the root is not sufficiently large to meet the water demand of the newly grown leaves.

In these equations $m(t)$ represents the partitioning of carbohydrates for growth of leaves during time $(t)$, and $c$ represents the ratio of stem to leaf weight which is constant for Vigna. $R(t)$ is the maximal rate of water uptake per root weight, and $f^{\prime}(R(t))$ defines the gain of water uptake per increase in root weight. $E$ is the transpiration rate per leaf area and $k$ is the relative water content of the leaves at which the plant operates. 


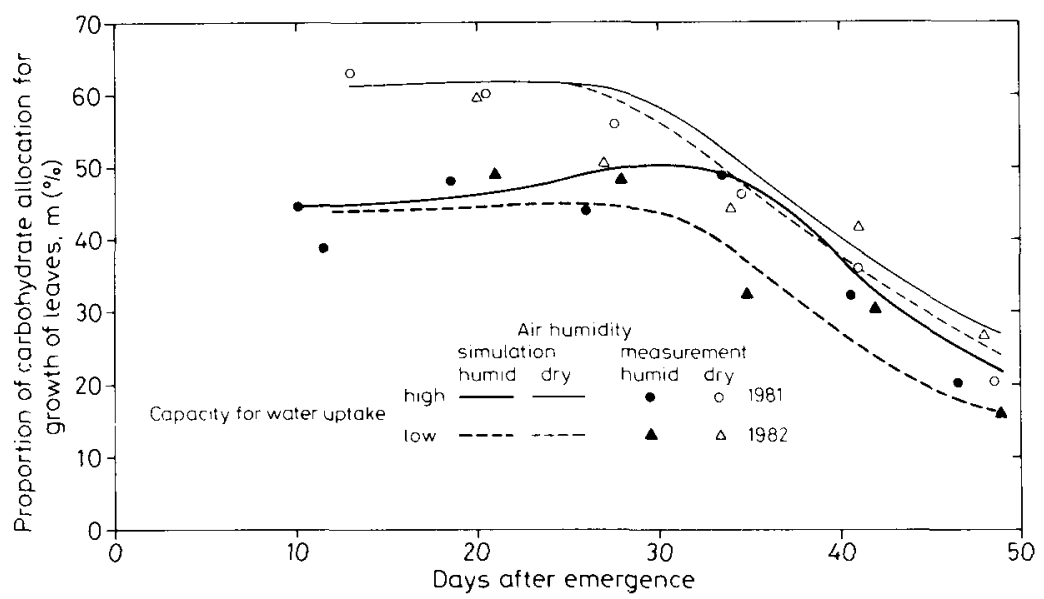

Fig. 6. Simulated (drawn lines) and measured (dots) proportions of carbohydrates partitioned for growth of leaves in Vigna unguiculata with a high and low capacity for water uptake (after Schulze et al., 1983a).

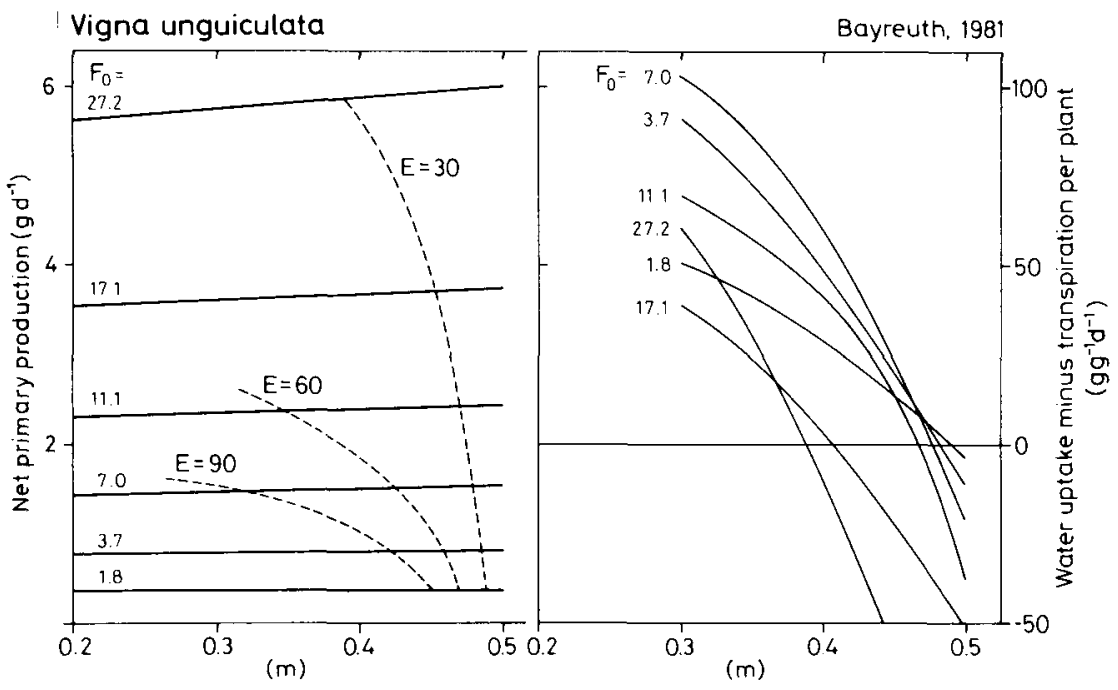

Fig. 7A (left). Net primary production, $P_{\mathrm{N}}$, as related to variations in carbon partitioning $(m)$ for growth of new leaves (solid lines). Net assimilation per leaf weight is $0.2 \mathrm{~g} \mathrm{~g}^{-1}$ day-1. $P_{\mathrm{N}}$ increases slightly with $m$. The lines do not go through the origin, since $P_{\mathrm{N}}$ of existing foliage will be greater than zero if no carbohydrates are channelled into growth of leaves. Different levels of $P_{\mathrm{N}}$ are due to different amounts of existing foliage, $F_{\mathrm{o}}$. The broken lines indicate the carbon-partitioning factor $(m)$ which is leading to the highest $P_{\mathrm{N}}$ at different levels of $F_{\mathrm{o}}$ and at different rates of transpiration $(E)$ per leaf weight, and without perturbing the water balance. This represents growth of Vigna unguiculata (after Schulze et al., 1983a or b). Fig. $7 \mathrm{~b}$ (right). The difference between whole plant water uptake and whole plant transpiration $(U-T)$ as related to variations in $(m)$. The lines represent different stages of growth with different amounts of existing leaf biomass, $F_{\mathrm{o}}$ (after Schulze et al., 1983).

Neth. J. agric. Sci. 31 (1983) 
Table 2. Carbon balance and increase in living-crown volume in a hedgerow. (After Küppers, 1982.)

\begin{tabular}{llll}
\hline & $\begin{array}{l}\text { Annual conversion rate of } \\
\mathrm{CO}_{2} \text { into leaf dry matter } \\
\left(\mathrm{mol} \mathrm{kg}^{-1} \mathrm{a}^{-1}\right)\end{array}$ & \multicolumn{2}{l}{ Quotient of volume increment of crown to } \\
\cline { 3 - 4 } & & $\begin{array}{l}\text { mass increment of } \\
\text { dry matter }\left(\mathrm{m}^{3} \mathrm{~kg}^{-1}\right)\end{array}$ & $\begin{array}{l}\text { mass of } \mathrm{CO}_{2} \text { assimilated } \\
\left(\mathrm{m}^{3} \mathrm{~kg}^{-1}\right)\end{array}$ \\
Prunus spinosa & 399 & 3.7 & 1.1 \\
Crataegus monogyna & 462 & 8.0 & 1.1 \\
Acer campestre & 332 & 10.3 & 2.3 \\
\hline
\end{tabular}

Fig. 6 shows predicted values of $m$, with pots in which only the water relations parameters and transpiration were determined, and measured values of $m$, determined independently from biomass assessments in different plants.

Variations in $m$ would influence water relations more than the production process (Fig. 7). An increase of $m$ will dramatically decrease the water balance, but it will only slightly increase net primary production, depending on the existing leaf biomass.

The results of the heuristic approach indicate that it is not sufficient just to determine biomass and root/shoot ratios. Rather, a description is needed of the way in which the production process varies with changes in partitioning. This is not just a problem of carbon relations but also a problem of water and nutrient supply which drives the process. In Vigna partitioning is determined mainly by the balance between the capacity of the root to take up water and the rate of transpiration.

The situation is quite different in woody species, where long-lived twigs and branches ensure a permanent enlargement of the shoot. Very complicated mechanisms determine the branching pattern and also leaf and bud development. The significance of the branching pattern and of leaf and bud development becomes obvious in a growth situation such as a European hedgerow, where numerous woody species compete for limited space. An analysis of the carbon relations shows (Table 2; Küppers, 1982) that Acer campestre, which is a dominating sub-tree in old hedgerows, has the lowest annual carbon gain when compared with Crataegus monogyna (typical bush of well-developed hedges) and Prunus spinosa, a spiny shrub of early successional stages, which protects Crataegus and Acer seedlings from browsing. However, Acer has the highest gain of crown volume per assimilated amount of $\mathrm{CO}_{2}$. It is not the weight of the shoots or the total amount of assimilated carbon, but the plant architecture which determines the succession and the success during competition of woody species.

The Vigna and Acer examples indicate that for understanding of plant growth and vegetative success of a species it is necessary to describe the carbon fluxes with respect to variations in partitioning and plant architecture. This is not only a problem of carbon relations and of root/shoot ratios, but also a problem of the water and nutrient supply. 


\section{References}

Allessio, M. L. \& L. L. Tieszen, 1978. Translocation and allocation of ${ }^{14} \mathrm{C}$-photoassimilate by Dupontia fisheri. In: L. L. Tieszen (Ed.), Vegetation and production ecology of an Alaskan arctic tundra. Ecol. Stud. Vol. 29. Springer, Berlin, Heidelberg, New York, pp. 393-413.

Chew, R. M. \& A. E. Chew, 1965. The primary productivity of a desert-shrub (Larrea tridentata) community. Ecol. Monogr. 35: 355-375.

Cowan, I. R. \& G. D. Farquhar, 1977. Stomatal function in relation to leaf metabolism and environment. In: D. H. Jennings (Ed.), Integration of activity in the higher plant. Cambridge University Press, Cambridge, pp. 471-505.

Fischer, R. A., 1975. Future role of physiology in wheat breeding. In: V. A. Johnson (Ed.), Proc. 2nd international winter wheat congress. Univ. Neb. Misc. Publ. 32: 178-196.

Hall, A. E. \& E.-D. Schulze, 1980. Stomatal response to environment and a possible interrelation between stomatal effects on transpiration and $\mathrm{CO}_{2}$ assimilation. Plant, Cell and Environment 3: 467-474.

Heim, G., J. J. Landsberg, R. L. Watson \& P. Brian, 1979. Eco-physiology of apple trees: Dry matter production and partitioning by young golden delicious trees in France and England. J. appl. Ecol. 16: 179-194.

Küppers, M., 1982. Kohlenstoffhaushalt, Wasserhaushalt, Wachstum und Wuchsform von Holzgewächsen im Konkurrenzgefüge eines Heckenstandortes. Diss. Universität Bayreuth.

Larcher, W., 1976. Ökologie der Pflanzen. UTB 232, 2nd ed. Ulmer, Stuttgart.

Monsi, M., 1960. Dry-matter reproduction in plants. I. Schemata of dry-matter reproduction. Bot. Mag. 73: 81-90.

Nagarajah, S. \& E.-D. Schulze, 1983. Responses of Vigna unguiculata (L.) Walp. to atmospheric and soil drought. Aust. J. Plant Physiol. (in print).

Schulze, E.-D., 1982. Plant life forms and their carbon, water and nutrient relations. Encyclopedia Plant Physiology N.S. Vol. 12B. Springer Verlag, Berlin, Heidelberg, New York, pp. 616-676.

Schulze, E.-D., K. Schilling \& S. Nagarajah, 1983a. Carbohydrate partitioning in relation to whole plant production and water use of Vigna unguiculata (L.) Walp. Oecologia 58: 169-177.

Schulze, E.-D., N. C. Turner \& Th. Gollan, 1983b. Interactions of plant water status and air humidity upon stomatal response, transpiration and $\mathrm{CO}_{2}$-assimilation. 2nd Annual Symposium of the SFB 137. Bayreuth.

Tietema, T., 1981. Ecophysiology of the sand sedge Carex arenaria L. Diss. State University of Utrecht. Wit, C. T. de, 1968. Plant production. Misc. Pap. Landbouwhogesch. Wageningen 3: 25-50. 